\title{
Anxiety level among nursing staff during the coronavirus disease 2019 pandemic: a cross-sectional study
}

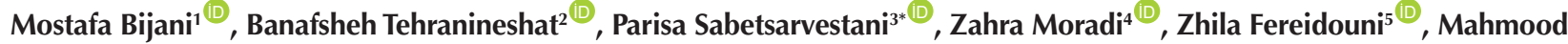 \\ Hatami $^{(\mathbb{D}}$, Tahereh Gholami ${ }^{\mathbb{1}}$ \\ ${ }^{1}$ Assistant Professor, School of Nursing, Fasa University of Medical Sciences \\ ${ }^{2}$ Assistant Professor, Community-Based Psychiatric Care Research Center, Department of Nursing, School of Nursing and \\ Midwifery, Shiraz University of Medical Sciences, Shiraz, Iran \\ ${ }^{3}$ Master of Nursing, School of Nursing, Fasa University of Medical Sciences Fasa, Iran \\ ${ }^{4}$ Department of Midwifery, School of Nursing, Fasa University of Medical Sciences, Fasa, Iran. \\ ${ }^{5}$ Associate Professor, School of Nursing, Fasa University of Medical Sciences Fasa, Iran \\ ${ }^{6}$ Master of Nursing, Department of Medical Surgical Nursing, Fasa University of Medical Sciences, Fasa, Iran \\ 'Department of Public Health, Fasa University of Medical Sciences, Fasa, Iran
}

\begin{abstract}
Background and aims: Emerging infectious diseases, such as coronavirus disease 2019 (COVID-19), are among the most serious occupational hazards for healthcare providers. The aim of the present study was to assess anxiety level among nursing staff during the COVID-19 pandemic.

Methods: This cross-sectional descriptive study was conducted in 2020. Participants were 510 nursing staff selected through a census from Valiasr teaching hospital, Fasa, Iran. Data were collected via a demographic questionnaire and a researcher-made COVID-19 anxiety questionnaire and were analyzed using the SPSS software (v. 22.0) through the chi square and ANOVA test.

Results: The total mean score of anxiety among participants was $93.10 \pm 7.06$ and had significant relationship with participants' age, work experience, affiliated ward, and educational level $(P<0.001)$.

Conclusion: Nursing staff suffer from high levels of anxiety during the COVID-19 pandemic. Healthcare authorities and managers need to employ strategies to psychologically support and empower nursing staff, improve their stress management skills, ensure their occupational safety, and improve their knowledge about COVID-19.
\end{abstract}

Keywords: Anxiety, Nursing, Coronavirus disease 2019
*Corresponding Author: Parisa Sabetsarvestani, Master of Nursing, School of Nursing, Fasa University of Medical Sciences Fasa, Iran. Tel:+989171898537, Email: Parisasabet244@yahoo. com

\section{Introduction}

Emerging diseases are infectious diseases that appear for the first time in one area, population, or the whole world, or have already existed but become more severe or drug resistant, or rapidly spread to other geographical areas $(1,2)$. According to the World Health Organization (WHO), there are currently over thirty emerging diseases with various types and levels of severity in the world (3). Coronavirus disease 2019 (COVID-19) is one of these diseases. COVID-19 was started in 2019 in China, rapidly spread throughout the world, and turned into a pandemic (4). In January 2020, the WHO described the COVID-19 pandemic as an alarming threat to international public health (5). The COVID-19 pandemic in Iran is more complex and severe. In October 2021, Iran was recovering from the fifth wave of the disease, while many countries are passing the second or the third wave. COVID-19 has so far affected more than 5.74 million people and caused more than 123000 deaths in Iran (6).

Nurses are the core of healthcare delivery system and play important roles in public health (7). They are in the frontline of care delivery to different patients, including patients with COVID-19 and hence, experience high levels of occupational stress and psychological strain $(7,8)$. Nurses in Iran also experienced different healthcare challenges during the five waves of COVID-19 (9). A study reported that compared with other healthcare providers, nurses experienced higher levels of depression and anxiety during care delivery to patients with COVID-19 (10). Another study showed that nurses experienced depression, anxiety, stress, and posttraumatic stress disorder in the COVID-19 pandemic (11).

The significant role of nurses in ensuring patient and public health and the high levels of psychological problems and emotional distress among them highlight the importance of devoting serious attention to their mental health (12) and the necessity of taking effective measures to ensure their occupational safety, particularly during infectious disease epidemics (13). An essential prerequisite to improve nurses' health and reduce their psychological problems is to assess their anxiety level and its contributing factors. However, to the best of our knowledge, limited studies had so far addressed anxiety during the COVID-19 pandemic among Iranian nurses.

( 2021 The Author(s); Published by Shahrekord University of Medical Sciences. This is an open-access article distributed under the terms of the Creative Commons Attribution License (http://creativecommons.org/licenses/by/4.0), which permits unrestricted use, distribution, and reproduction in any medium, provided the original work is properly cited. 
Therefore, the present study sought to narrow this gap. The aim of the study was to assess anxiety level among nursing staff during the COVID-19 pandemic.

\section{Methods}

Design

This cross-sectional descriptive study was conducted in 2020.

\section{Participants and setting}

Eligible study participants were all 670 nursing staff of Valiasr teaching hospital, Fasa, Iran. Accordingly, all nurses who agreed to participate were recruited to the study through a census. The only exclusion criterion was incomplete answering to the study instruments.

\section{Instrument and data collection}

Data collection instruments were a demographic questionnaire and a researcher-made COVID-19 anxiety questionnaire. The items of the demographic questionnaire were on age, gender, work experience, educational level, and affiliated ward. The researcher-made COVID-19 anxiety questionnaire consisted of twenty items scored on a five-point Likert scale from 5 ("Extremely") to 1 ("Very little"). The possible total score of the questionnaire was 20-100 and was interpreted as follows: scores 20-50: low anxiety; scores 51-70: moderate anxiety; and 71-100: great anxiety. For quantitative face validity assessment of the questionnaire, twenty nursing instructors rated item importance and then, item impact scores were calculated to be more than 1.5 and confirmed the acceptable face validity of the questionnaire (14). Content validity ratio and index were calculated for content validity assessment. Accordingly, fifteen nursing instructors rated the essentiality of the items and the content validity ratios of all items were calculated which were more than the minimum critical value of 0.49 (15). The same experts were also asked to rate the relevance, clarity, and simplicity of the items and then, their rating scores were used to calculate content validity index. All items had a content validity index of more than 0.79 (15). The reliability of the questionnaire was evaluated through the test-retest stability assessment, in which fifty nurses twice completed the questionnaire with a two-week interval. The test-retest correlation coefficient of the questionnaire was 0.90 and the reliability of the questionnaire was confirmed (16). In order to prevent COVID-19 transmission to participants, they were asked to complete the study instruments online. The link of the instrument was sent to participants through the WhatsApp.

\section{Data analysis}

The SPSS software (v. 22.0) was employed to analyze the data through the chi square and ANOVA test and the oneway analysis of variance. The level of significance was set at less than 0.05 .

\section{Results}

A total of 670 nursing staff were invited to the study and 510 of them completely answered the study instruments (response rate 76\%). Most participants were female (60.19\%) and held bachelor's degree (88.43\%) (Table 1). The means of participants' age and work experience were $35.98 \pm 6.73$ and $10.68 \pm 4.87$ years, respectively.

The total mean score of anxiety among participants was $93.10 \pm 7.06$ and the five highest scored items of the anxiety questionnaire were items on regret about choosing nursing after COVID-19 outbreak (mean: $5.00 \pm 0.35$ ), ability to enjoy life after affliction by COVID-19 (mean: 4.94 \pm 0.26 ), worry about personal health in the COVID-19 crisis (mean: 4.85 \pm 0.47 ), worry about transmitting COVID-19 to family members (mean: $4.85 \pm 0.47$ ), and effects of COVID-19 on social and occupational activities (mean: $4.84 \pm 0.48$ ) (Table 2). The total mean score of participants' anxiety had significant relationship with their age, work experience, affiliated ward, and educational level $(P<$ $0.001)$, but had no significant relationship with their gender $(P=0.165)$ (Table 1$)$.

\section{Discussion}

This study assessed anxiety level among nursing staff during the COVID-19 pandemic. Findings showed that the mean score of anxiety among nursing staff was 93.10 \pm 7.06, which implies high anxiety level. Similarly, a study on Chinese nurses showed that they experienced

Table 1. Participants' demographic characteristics and mean scores of anxiety

\begin{tabular}{|c|c|c|c|c|}
\hline \multicolumn{2}{|c|}{ Characteristics } & \multirow{2}{*}{$\frac{\text { No. (\%) }}{203(39.80)}$} & \multirow{2}{*}{$\frac{\text { Mean } \pm \text { SD }}{92.56 \pm 7.76}$} & \multirow{3}{*}{$\begin{array}{l}\boldsymbol{P} \text { value } \\
0.165^{*}\end{array}$} \\
\hline \multirow{2}{*}{ Gender } & Male & & & \\
\hline & Female & $307(60.19)$ & $93.45 \pm 6.54$ & \\
\hline \multirow{3}{*}{$\begin{array}{l}\text { Educational } \\
\text { level }\end{array}$} & Bachelor's & $451(88.43)$ & $94.35 \pm 5.76$ & \multirow{3}{*}{$<0.001 *$} \\
\hline & Master's & $42(7.7)$ & $85.45 \pm 8.83$ & \\
\hline & Ph.D. & $17(3.1)$ & $78.82 \pm 6.08$ & \\
\hline \multirow{3}{*}{ Age $(y)$} & $23-33$ & $154(28.1)$ & $95.63 \pm 1.01$ & \multirow{3}{*}{$<0.001^{* *}$} \\
\hline & $34-43$ & $288(51.5)$ & $93.13 \pm 6.90$ & \\
\hline & $44-53$ & $78(13.3)$ & $87.54 \pm 10.93$ & \\
\hline \multirow{4}{*}{$\begin{array}{l}\text { Work } \\
\text { experiences } \\
\text { (y) }\end{array}$} & $1-5$ & $100(18.2)$ & $95.97 \pm 1.13$ & \multirow{4}{*}{$<0.001^{* *}$} \\
\hline & $6-10$ & $128(23.3)$ & $95.05 \pm 0.19$ & \\
\hline & $11-15$ & $195(35.5)$ & $92.70 \pm 8.42$ & \\
\hline & $>16$ & $87(15.8)$ & $87.80 \pm 9.50$ & \\
\hline \multirow{10}{*}{$\begin{array}{l}\text { Affiliated } \\
\text { ward }\end{array}$} & Emergency & $124(22.6)$ & $97.82 \pm 0.98$ & \multirow{10}{*}{$<0.001 *$} \\
\hline & Internal medicine & $67(12.2)$ & $95.75 \pm 0.91$ & \\
\hline & Men's surgical & $32(5.8)$ & $95.09 \pm 0.39$ & \\
\hline & Women's surgical & $42(7.7)$ & $95.76 \pm 0.43$ & \\
\hline & Coronary care & $40(7.3)$ & $79.6 \pm 10.24$ & \\
\hline & Intensive care & $48(8.7)$ & $95.77 \pm 0.42$ & \\
\hline & Infectious disease & $47(8.6)$ & $95.74 \pm 0.90$ & \\
\hline & Neonatal care & $51(9.3)$ & $97.22 \pm 3.71$ & \\
\hline & Dialysis & 27 (4.9) & $90.55 \pm 2.57$ & \\
\hline & Neurology & $32(5.8)$ & $77.62 \pm 7.4$ & \\
\hline
\end{tabular}

\footnotetext{
*Chi-square test.
}

**ANOVA test. 
Table 2. The mean scores of the COVID-19 anxiety questionnaire and its items

\begin{tabular}{|c|c|c|}
\hline No. & Items & Mean \pm SD \\
\hline 1 & Are you worried about your health in the COVID-19 pandemic? & $4.74 \pm 0.23$ \\
\hline 2 & Do you pay attention to the complications of COVID-19? & $4.77 \pm 0.52$ \\
\hline 3 & Are you aware of your feelings or bodily changes? & $4.80 \pm 0.50$ \\
\hline 4 & How do you rate your colleagues' COVID-19-related stress? & $4.80 \pm 0.48$ \\
\hline 5 & Do you have any fear over affliction by COVID-19? & $4.78 \pm 0.51$ \\
\hline 6 & Do you think you are afflicted by COVID-19? & $4.76 \pm 0.58$ \\
\hline 7 & Do you have the necessary ability to put aside thoughts about COVID-19? & $4.80 \pm 0.49$ \\
\hline 8 & Do you think you will feel comfortable after a physician tells you that you are not afflicted by COVID-19? & $4.79 \pm 0.53$ \\
\hline 9 & Can you tolerate to hear the news of your affliction by COVID-19? & $4.80 \pm 0.52$ \\
\hline 10 & Are you more sensitized to your feelings or bodily changes compared with the past? & $4.76 \pm 0.57$ \\
\hline 11 & Do you feel you are at risk for affliction by COVID-19? & $4.52 \pm 0.64$ \\
\hline 12 & Do you think about affliction by COVID-19? & $4.83 \pm 0.15$ \\
\hline 13 & Do you attribute any unusual physical symptom to COVID-19? & $4.51 \pm 0.71$ \\
\hline 14 & Are you worried about the available medical services and equipment for COVID-19? & $4.80 \pm 0.53$ \\
\hline 15 & Do you have the ability to enjoy life if you are afflicted by COVID-19? & $4.84 \pm 0.19$ \\
\hline 16 & Do you feel you will recover from COVID-19 if you are afflicted by it? & $4.29 \pm 0.55$ \\
\hline 17 & Do you think your social and occupational activities are affected by COVID-19? & $4.73 \pm 0.28$ \\
\hline 18 & Do you think you will lose your social status and dignity due to COVID-19? & $3.41 \pm 0.78$ \\
\hline 19 & Do you think it would be better to choose another job after the COVID-19 outbreak? & $4.92 \pm 0.16$ \\
\hline \multirow[t]{2}{*}{20} & Are you worried about transmission of COVID-19 to family members? & $4.59 \pm 0.39$ \\
\hline & Total & $93.10 \pm 7.06$ \\
\hline
\end{tabular}

extreme anxiety and stress due to their exposure to COVID-19 (17). A cross-sectional study in Wuhan, China, at the time of the COVID-19 outbreak also reported that more than half of the 994 studied physicians and nurses suffered from high levels of anxiety and depression (18). A study in Turkey also reported that nurses who delivered care to COVID-19 patients experienced higher levels of anxiety than other nurses and needed education about psychological empowerment, resilience, and anxiety management (19). Three studies on nurses in Iran during the COVID-19 pandemic also revealed that they had high levels of anxiety. High levels of anxiety among nurses can lead to problems such as fatigue, impaired concentration, sleep disturbances, decreased resilience, job burnout, and mental health problems (20-22). Although care delivery is a respectable and valuable occupation, it exposes healthcare providers to different occupational hazards (12). For example, dealing with emerging infectious diseases is associated with different physical, emotional, and financial problems for healthcare providers and hence, is considered as a major concern for them $(23,24)$.

Our findings also showed that nursing staff's anxiety level had significant relationship with their affiliated ward so that nursing staff in emergency, infectious disease, and intensive care wards had higher anxiety levels compared to their colleagues in other wards. In line with this finding, a former study showed that nurses in emergency wards experienced higher levels of stress and anxiety than other nurses (25). Another study reported that emergency ward is a very stressful environment and emergency nurses experience considerable physical and psychological strain (26). The high level of anxiety among nursing staff in emergency, infectious disease, and intensive care wards may be due to the large number of patients, unpredictable changes in patients' conditions, and heavy workload in these wards (27-29). Psychological empowerment of nurses and improvement their skills of effective coping with occupational stress can significantly improve their quality of working life and the quality of their care services. Therefore, nursing managers should hold educational workshops to improve nurses' stress management skills and resilience and empower them for effective management of stressful situations (26).

We also found that anxiety level had significant relationship with age and work experience. A former study also reported the same finding (30). Nurses with older age and greater work experience are more able to cope with stressful situations and can better manage crises than their less experienced colleagues $(31,32)$.

Contrary to our findings, a former study on nurses reported that anxiety had no significant relationship with demographic characteristics (33). This contradiction may be due to the differences between studies with respect to study population and sample size (33).

\section{Limitations}

This study only assessed nursing staff's anxiety level during the COVID-19 pandemic. Future studies are recommended to assess other health-related outcomes such as depression and resilience among nurses. Moreover, 
What does this paper contribute to the wider global clinical community?

- $\quad$ Nursing staff experience high levels of anxiety during the COVID-19 pandemic.

- The level of anxiety among nursing staff during the COVID-19 pandemic has significant relationship with their age, work experience, affiliated ward, and educational level.

- Effective strategies are needed to psychologically support and empower nursing staff, improve their stress management skills, ensure their occupational safety, and improve their knowledge about COVID-19.

qualitative and interventional studies are needed to produce more evidence respecting anxiety level among nursing staff during the COVID-19 pandemic.

\section{Conclusion}

This study shows the high levels of anxiety among nursing staff during the COVID-19 pandemic. Healthcare authorities and nursing managers are recommended to make environmental improvements and use strategies to support nurses during crises such as the COVID-19 pandemic.

\section{Authors' Contribution}

$\mathrm{PS}, \mathrm{BT}, \mathrm{ZM}$, and $\mathrm{MB}$ contributed to the conception of the study and interpretation of the data. ZF, MH, and TG contributed to data collection and analysis. PS and MB drafted the manuscript and approved its final version.

\section{Conflict of Interests}

None is declared.

\section{Ethical Approval}

The Ethics Committee of Fasa University of Medical Sciences, Fasa, Iran, approved this study (code: IR.FUMS.REC.1398.196). Nursing staff voluntarily participated in the study and provided informed consent for participation.

\section{Funding/Support}

The Research and Technology Administration of Fasa University of Medical Sciences, Fasa, Iran, and the Center for Clinical Research Development of Valiasr hospital, Fasa, Iran, supported this study.

\section{Acknowledgement}

We would like to thank all nurses who participated in the study as well as the Research and Technology Administration of Fasa University of Medical Sciences, Fasa, Iran, and the Clinical Research Development Center of Valiasr hospital, Fasa, Iran, for supporting this study.

\section{References}

1. Wang D, Hu B, Hu C, Zhu F, Liu X, Zhang J, et al. Clinical characteristics of 138 hospitalized patients with 2019 novel coronavirus-infected pneumonia in Wuhan, China. JAMA. 2020;323(11):1061-9. doi: 10.1001/jama.2020.1585.

2. Huang C, Wang Y, Li X, Ren L, Zhao J, Hu Y, et al. Clinical features of patients infected with 2019 novel coronavirus in Wuhan, China. Lancet. 2020;395(10223):497-506. doi: 10.1016/s0140-6736(20)30183-5.

3. Habibzadeh P, Stoneman EK. The novel coronavirus: a bird's eye view. Int J Occup Environ Med. 2020;11(2):65-71. doi: 10.15171/ijoem.2020.1921.

4. Lai CC, Shih TP, Ko WC, Tang HJ, Hsueh PR. Severe acute respiratory syndrome coronavirus 2 (SARS-CoV-2) and coronavirus disease-2019 (COVID-19): the epidemic and the challenges. Int J Antimicrob Agents. 2020;55(3):105924. doi: 10.1016/j.ijantimicag.2020.105924.

5. World Health Organization (WHO). Clinical Management of Severe Acute Respiratory Infection (SARI)" when COVID-19 Disease is Suspected: Interim Guidance, 13 March 2020. WHO; 2020. Available at: https://apps.who.int/iris/bitstream/ handle/10665/331446/WHO-2019-nCoV-clinical-2020.4chi.pdf.

6. Yoosefi Lebni J, Abbas J, Moradi F, Salahshoor MR, Chaboksavar F, Irandoost SF, et al. How the COVID-19 pandemic effected economic, social, political, and cultural factors: A lesson from Iran. Int J Soc Psychiatry. 2021;67(3):298-300. doi: 10.1177/0020764020939984.

7. Bartlett ML, Taylor H, Nelson JD. Comparison of mental health characteristics and stress between baccalaureate nursing students and non-nursing students. J Nurs Educ. 2016;55(2):87-90. doi: 10.3928/01484834-20160114-05.

8. Wang J, Zhou M, Liu F. Reasons for healthcare workers becoming infected with novel coronavirus disease 2019 (COVID-19) in China. J Hosp Infect. 2020;105(1):100-1. doi: 10.1016/j.jhin.2020.03.002.

9. Khanmohammadi S, Hajibeglo A, Rashidan M, Bekmaz K. Relationship of resilience with occupational stress among nurses in coronavirus ward of Khatam Al-Anbia Hospital, Gonbad Kavous, 2020. Neuropsychiatr i Neuropsychol. 2020;15(1-2):1-6.

10. Lai J, Ma S, Wang Y, Cai Z, Hu J, Wei N, et al. Factors associated with mental health outcomes among health care workers exposed to coronavirus disease 2019. JAMA Netw Open. 2020;3(3):e203976. doi: 10.1001/ jamanetworkopen.2020.3976.

11. Roy D, Tripathy S, Kar SK, Sharma N, Verma SK, Kaushal V. Study of knowledge, attitude, anxiety \& perceived mental healthcare need in Indian population during COVID-19 pandemic. Asian J Psychiatr. 2020;51:102083. doi: 10.1016/j. ajp.2020.102083.

12. Kang L, Li Y, Hu S, Chen M, Yang C, Yang BX, et al. The mental health of medical workers in Wuhan, China dealing with the 2019 novel coronavirus. Lancet Psychiatry. 2020;7(3):e14. doi: 10.1016/s2215-0366(20)30047-x.

13. Spoorthy MS, Pratapa SK, Mahant S. Mental health problems faced by healthcare workers due to the COVID-19 pandemic-a review. Asian J Psychiatr. 2020;51:102119. doi: 10.1016/j. ajp.2020.102119.

14. Connell J, Carlton J, Grundy A, Taylor Buck E, Keetharuth AD, Ricketts $T$, et al. The importance of content and face validity in instrument development: lessons learnt from service users when developing the Recovering Quality of Life measure (ReQoL). Qual Life Res. 2018;27(7):1893-902. doi: 10.1007/ s11136-018-1847-y.

15. Ayre C, Scally AJ. Critical values for Lawshe's content validity ratio: revisiting the original methods of calculation. Meas Eval Couns Dev. 2014;47(1):79-86. doi: 10.1177/0748175613513808.

16. Heale R, Twycross A. Validity and reliability in quantitative studies. Evid Based Nurs. 2015;18(3):66-7. doi: 10.1136/eb2015-102129.

17. Mo Y, Deng L, Zhang L, Lang Q, Liao C, Wang N, et al. Work stress among Chinese nurses to support Wuhan in fighting against COVID-19 epidemic. J Nurs Manag. 2020;28(5):10029. doi: 10.1111/jonm.13014.

18. Kang L, Ma S, Chen M, Yang J, Wang Y, Li R, et al. Impact on mental health and perceptions of psychological care among 
medical and nursing staff in Wuhan during the 2019 novel coronavirus disease outbreak: a cross-sectional study. Brain Behav Immun. 2020;87:11-7. doi: 10.1016/j.bbi.2020.03.028.

19. Bostan S, Akbolat M, Kaya A, Ozata M, Gunes D. Assessments of anxiety levels and working conditions of health employees working in COVİD-19 pandemic hospitals. Electron J Gen Med. 2020;17(5):em246. doi: 10.29333/ejgm/8228.

20. Karimi Z, Fereidouni Z, Behnammoghadam M, Alimohammadi N, Mousavizadeh A, Salehi T, et al. The lived experience of nurses caring for patients with COVID-19 in Iran: a phenomenological study. Risk Manag Healthc Policy. 2020;13:1271-8. doi: 10.2147/rmhp.s258785.

21. Mohammadi F, Farjam M, Gholampour $Y$, Sohrabpour $M$, Oshvandi K, Bijani M. Caregivers' perception of the caring challenges in coronavirus crisis (COVID-19): a qualitative study. BMC Nurs. 2021;20(1):102. doi: 10.1186/s12912-02100607-1.

22. Al Maqbali M, Al Sinani M, Al-Lenjawi B. Prevalence of stress, depression, anxiety and sleep disturbance among nurses during the COVID-19 pandemic: a systematic review and meta-analysis. J Psychosom Res. 2021;141:110343. doi: 10.1016/j.jpsychores.2020.110343.

23. Cai H, Tu B, Ma J, Chen L, Fu L, Jiang Y, et al. Psychological impact and coping strategies of frontline medical staff in Hunan between January and March 2020 during the outbreak of coronavirus disease 2019 (COVID-19) in Hubei, China. Med Sci Monit. 2020;26:e924171. doi: 10.12659/msm.924171.

24. Ho CS, Chee CY, Ho RC. Mental health strategies to combat the psychological impact of coronavirus disease 2019 (COVID-19) beyond paranoia and panic. Ann Acad Med Singap. 2020;49(3):155-60.

25. Shareinia H, Khuniki F, Bloochi Beydokhti T, Eydi Zeynabad A, Hosseini M. Comparison between job stress among emergency department nurses with nurses of other departments. Quarterly
Journal of Nursing Management. 2018;6(3):48-56. doi: 10.29252/ijnv.6.3.4.48. [Persian].

26. Singh GP. Job stress among emergency nursing staff: a preliminary study. Indian J Psychiatry. 2013;55(4):407-8. doi: 10.4103/0019-5545.120574.

27. Nemati M, Ebrahimi B, Nemati F. Assessment of Iranian nurses' knowledge and anxiety toward COVID-19 during the current outbreak in Iran. Arch Clin Infect Dis. 2020;15(COVID19):e102848. doi: 10.5812/archcid.102848.

28. Kumar A, Pore P, Gupta S, Wani AO. Level of stress and its determinants among intensive care unit staff. Indian J Occup Environ Med. 2016;20(3):129-32. doi: 10.4103/00195278.203137

29. Lam SKK, Kwong EWY, Hung MSY, Pang SMC, Chien WT. A qualitative descriptive study of the contextual factors influencing the practice of emergency nurses in managing emerging infectious diseases. Int J Qual Stud Health Well-being. 2019;14(1):1626179. doi: 10.1080/17482631.2019.1626179.

30. Mortaghi Ghasemi M, Ghahremani Z, Vahedian Azimi A, Ghorbani F. Nurses job stress in therapeutic educational centers in Zanjan. J Res Dev Nurs Midwifery. 2011;8(1):4251. [Persian].

31. Maharaj S, Lees T, Lal S. Prevalence and risk factors of depression, anxiety, and stress in a cohort of Australian nurses. Int J Environ Res Public Health. 2018;16(1):61. doi: 10.3390/ ijerph16010061.

32. Rana W, Mukhtar S, Mukhtar S. Mental health of medical workers in Pakistan during the pandemic COVID-19 outbreak. Asian J Psychiatr. 2020;51:102080. doi: 10.1016/j. ajp.2020.102080.

33. Romano M, Festini F, Bronner L. [Cross-sectional study on the determinants of work stress for nurses and intention of leaving the profession]. Prof Inferm. 2015;68(4):203-10. doi: 10.7429/ pi.2015.684203. [Italian].

Cite this article as: Bijani M, Tehranineshat B, Sabetsarvestani P, Moradi Z, Fereidouni Z, Hatami M, et al. Anxiety level among nursing staff during the coronavirus disease 2019 pandemic: a cross-sectional study. Journal of Multidisciplinary Care. 2021;10(3):111-115. doi: 10.34172/jmdc.2021.22. 